M. Darvishi ${ }^{1}$, Z. Ghazi Vakili ${ }^{2}$, A. J. Mohammadi ${ }^{3}$

1. MS in Nursing, Alborz University of Medical

Sciences and Health Services

2. MS in Midwifery, Alborz University of Medical Sciences and Health Services

3. Ph.D Student in Health Care Management, Islamic Azad University, Science and Research

*Corresponding Author: $\mathrm{PhD}$ Student in Health Care Management, Islamic Azad University, Science and Research Branch, Tehran

Tel: 0912-3606462

E-mail: Alijamalmohammadi@yahoo.com

\section{The Relationship Between Religious Beliefs and Mental Health in Students of Alborz University of Medical Sciences and Health Services and Karaj Islamic Azad University in 92-93}

Received: 2 Nov. 2016 ; Accepted: 3 Apr.2017

Introduction and Goal: We as a society in transition countries grapple with issues. Including the issues of youth unemployment, the economic, social, cultural and others. The increasing tendency of students to imitate the western culture And the duplication of a part of western culture and identity today emptiness of the west And moral collapse brought and glamor that can be said for our youth no entertainment, sports and leisure programs for their healthy catchy and their needs and the vacuum created in imitation of the vulgar aspects of western culture that quickly spread in our society to our young people away from having ideas is healthy and know the distance of this group of noble and religious values. students based on academic and social issues specific pressure groups are at risk. According to Islamic texts adherence to religious beliefs can be a deterrent lot of mental illness. increased attention to this issue across the world, the importance of religion and represents a return to religion and spirituality. According to the study on health and religion is still in its infancy and mental health in ensuring the dynamics of this segment of society that is dependent on medical students is important, It seems that the implementation of such researches to improve the level of social and religious knowledge students have an important role.

Methods: This cross-sectional study (descriptive - analysis), the population of all students studying medical sciences universities in Tehran and Karaj Islamic Azad form. of the population. According to the study, the sample of 377 randomly selected subjects and to prevent the loss of samples, ten percent was added to the sample (415 people) and of these 404 people filled out the questionnaire responded. Three demographic information, general health and religious beliefs to collect data in order to achieve the objectives of the study were analyzed using descriptive statistics. After data collection, data processing and the purposes of the study using SPSS descriptive statistics (frequency, mean, standard deviation) and inferential statistics (independent $t$ test, Pearson and ANOVA) for analysis the data was used.

Results: The results showed that between religious affiliation and sex, age and school year, there is no significant relationship ( $p>0.05)$. In the relationship between religious affiliation, various aspects of mental health and other variables were observed between religious affiliation and gender, the level of anxiety and depression There is a significant relationship. But there is no relationship between the level of somatic symptoms and social functioning subscale there weakly $(p<0.05)$.

Conclusion: The results show that the religious affiliation of individuals based on gender can predict a person's sense of anxiety and depression.

Keywords: Religious Orientation, Mental Health 


\section{بر رسى ارتباط بين اعتقادات مذهبى و سلامت روان در دانشجويان دانشكاههاى

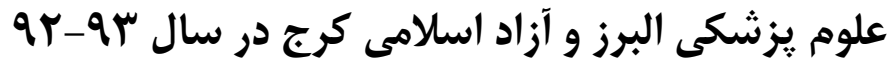

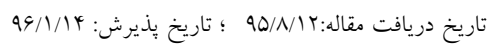

مقدمه و هدف: كشور ما به عنوان يكى جامعه در حال كذار با مسائلى دست به كريبان است. از جمله اين مسائل جوانان،

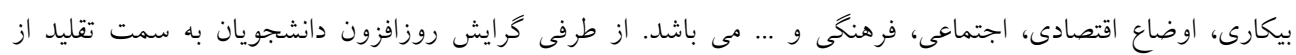

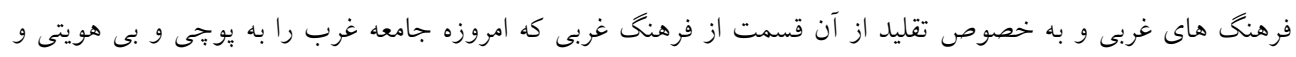

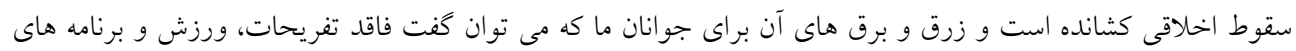

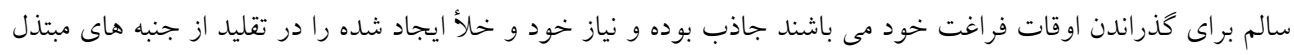

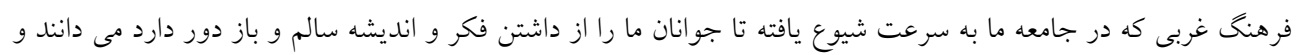

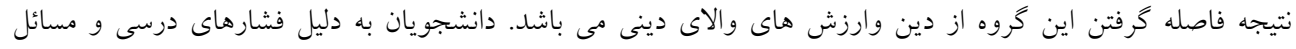

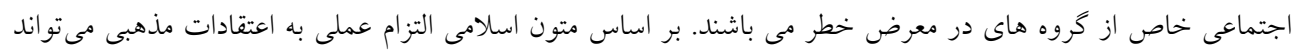

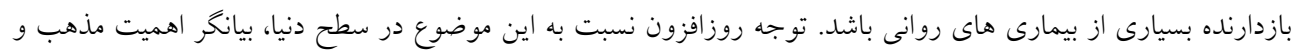

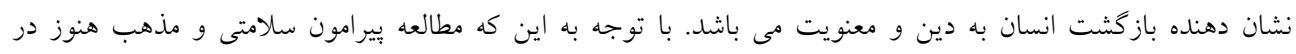

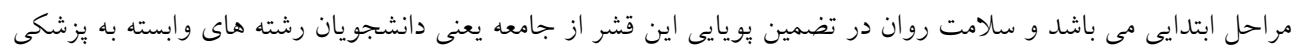

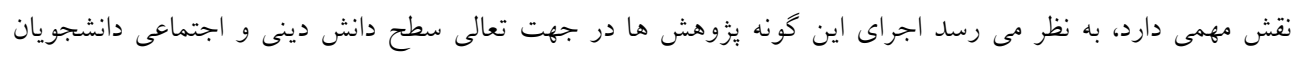
نقش به سزايى داشته باشد.

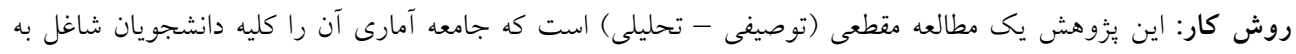

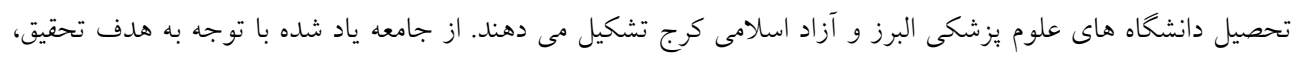

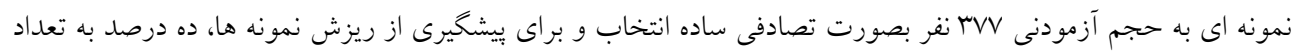

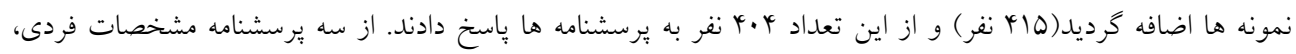

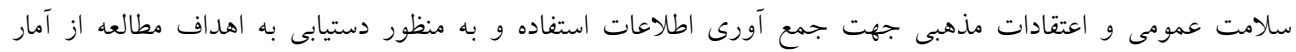

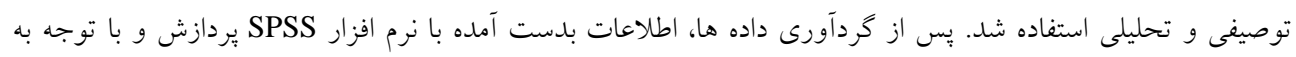

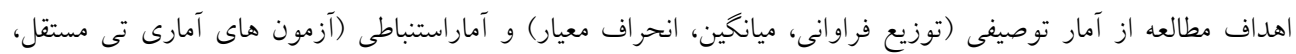

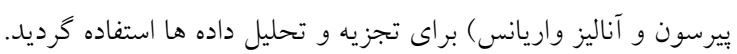

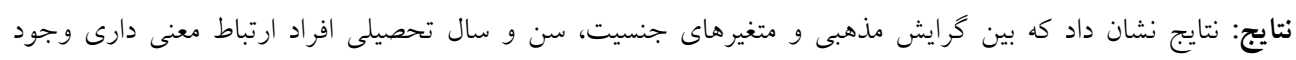

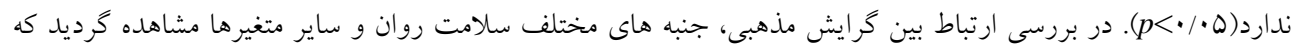

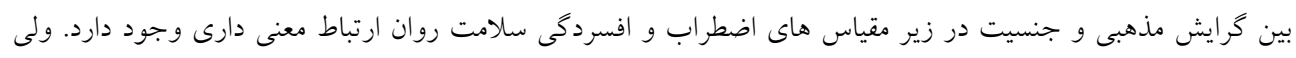

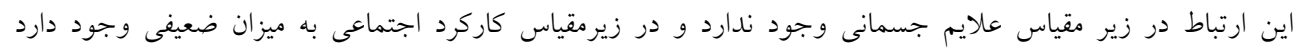

. $(p<\cdot / \cdot 0)$ نتيجه گيرى: نتايج بيانكر اين است كه ميزان كرايش مذهبى افراد برحسب جنسيت مى تواند ميزان احساس اضطراب و افسردكى فرد را بيش بينى نمايد. كلمات كليدى: كرايش مذهبي، سلامت روان 
بر اين عقيدهاند كه سلامت روان كليد رضايتمندى از زنـــى اسـت

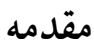
و فراتر از فقدان يا نبود بيمارى روانى است. سازمان جهانى بهلداشت، سلامتى را يكى حالت رفاه فيزيكى، روانى و اجتماعى مىداند نهفقط لنط

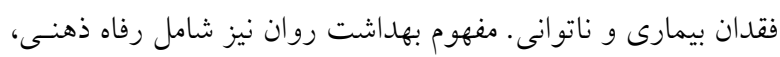
احساس خود توانمندى، خودمختارى ،كفايت، درك، همبستكى بـين ولين نسلى و توانايى تشخيص استعدادهاى بالقوه هوشى و عاطفى در خود

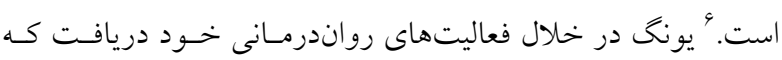

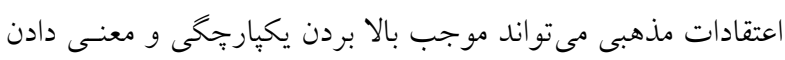

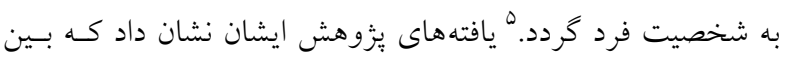

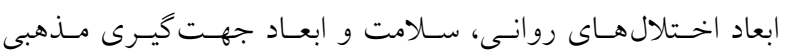
همبستخى وجود دارد. ازآنجايى كه هر گونه دخالت درزمينـه مسـائل روانى محتاج شناخت كافى از روان انسان بوده و تنها خداوند است كه شناخت كاملى از روان انسان دارد ازايسنرو احكـام و دسـتورات دينى نشست گرفته از علم الهى مى تواند اطلاعات جامعى در مـورد

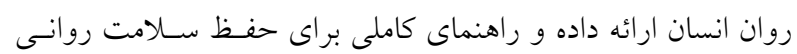

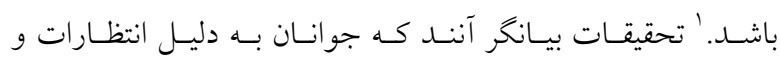
ناكامى هاى گسترده خود نسبت به سـاير گـروههـاى سـنى بيشـتر در

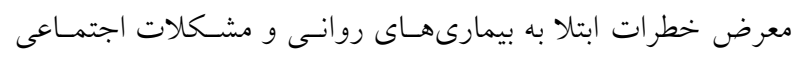

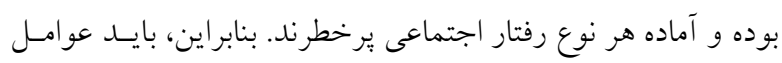

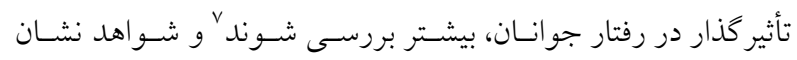

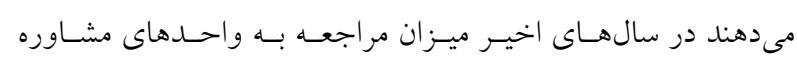

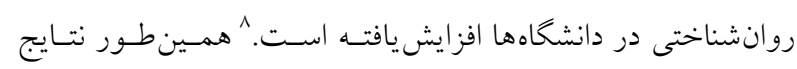

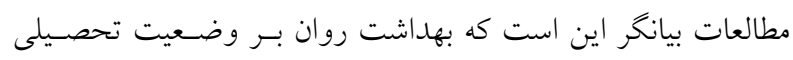

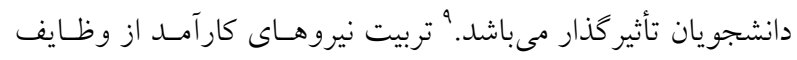
اصلى دانشخاهها مىباشد و افزايش سـطح علمسى و كـار آيى كثــور

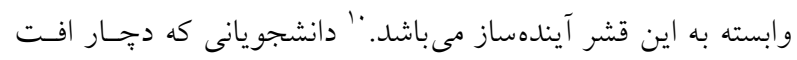

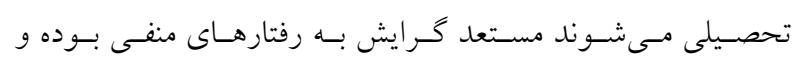
خساراتى را به خود و جامعه وارد مى كنند." بسيارى از دانشسجويان

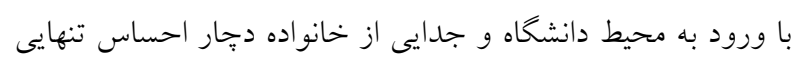

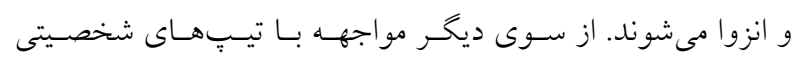
مختلف در محيط حرفهاى و خوابكاه، عدمكفايت امكانـات رفـاهى،

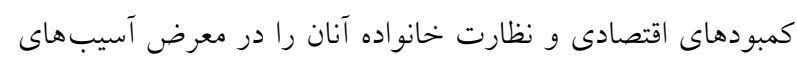
روانى و اجتماعى قرار مىدهد و احتمال رفتارهاى برخطر اجتماعى ونى 
دانشجويان دانشگاه علوم يزشكى شهركرد انجام دادند، يافتها نشان

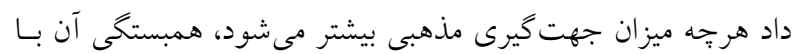

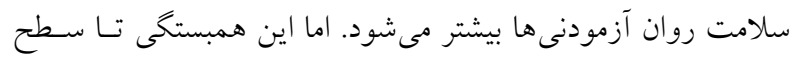

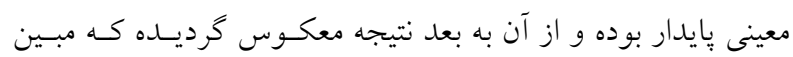

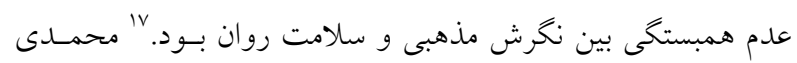

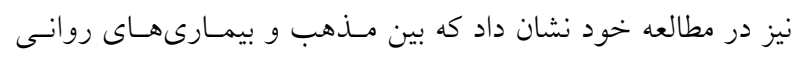

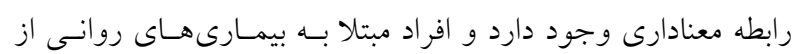
لحاظ مذهبى ضعيفتر از افراد سالم هستند." بهرامسى و تمنـايى فـر

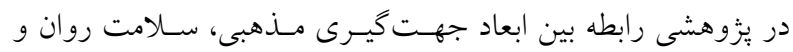

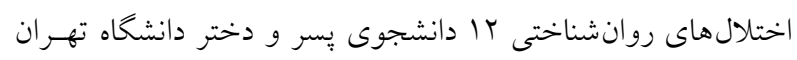

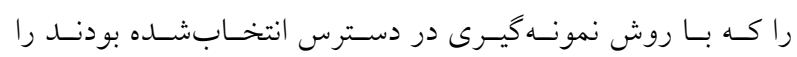

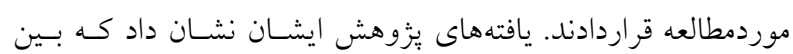

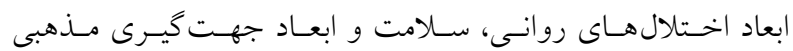

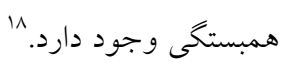

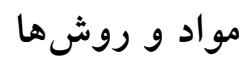

اين مطالعه يك مطالعه توصسيفى - تحليلسى بـوده و بـه بررسى رسى

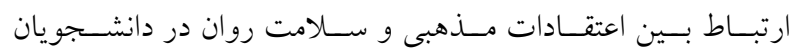

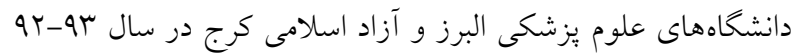

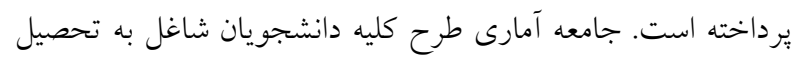

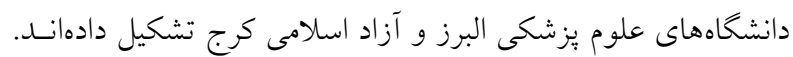

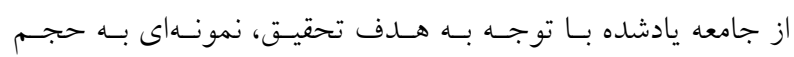

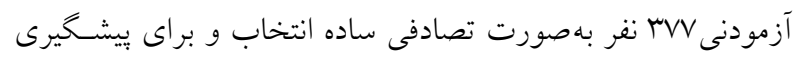

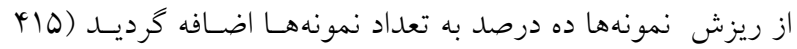

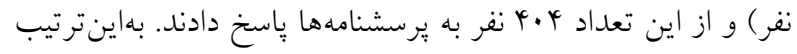

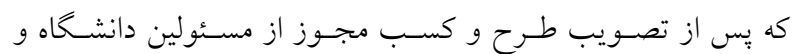
هماهنگى با روساى دانشكدهها، يرسشنامههاى اسـتاندارد در اختيـار

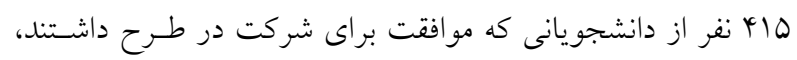
قرار داده شد. بِ از توضيح در خصوص نحوه باسخدهى، به آنـان

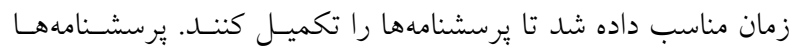

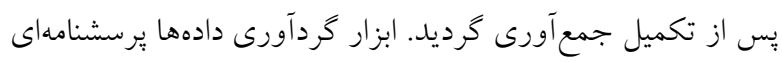

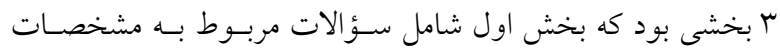

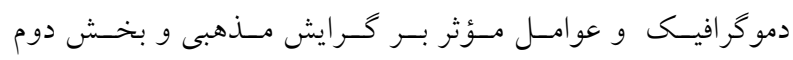
ير سشنامههاى استانداردشده سلامت روان بـود. يرسشــامه سـلامت

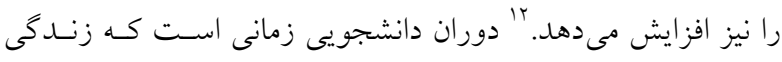

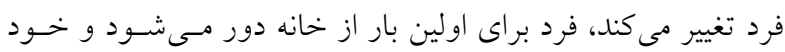
تصميم گيرى مى كند. تحقيقات انجامشده نشان مىدهد كه در محيط فيط

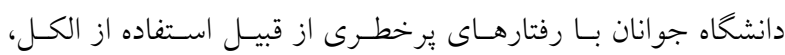

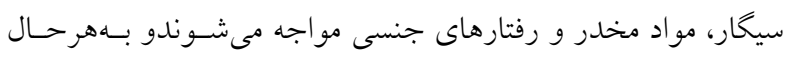

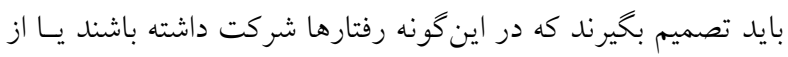
آنها دورى نمايند كه عوامل مختلف شخصيتى، اجتماعى و معرفتى

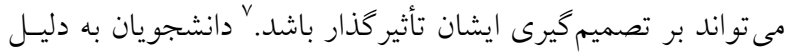

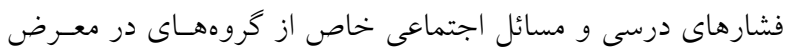

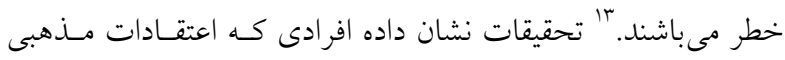

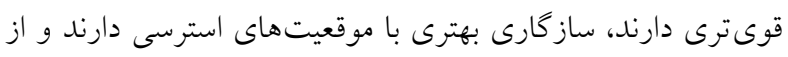
عملكرد تحصيلى و حمايت اجتماعى بالاترى برخوردارند اضطراب

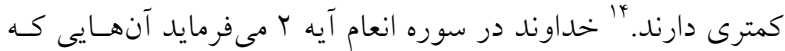

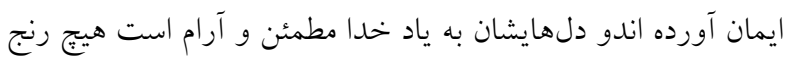

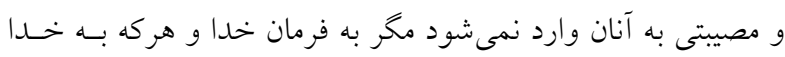

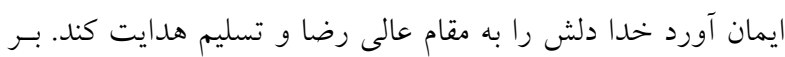

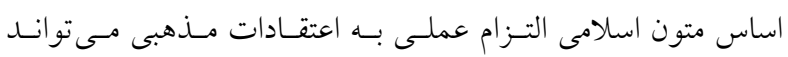

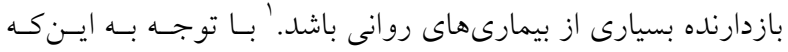

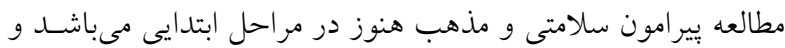
سلامت روان در تضمين يويايى اين قشر از جامعه يعنى دانشجويان

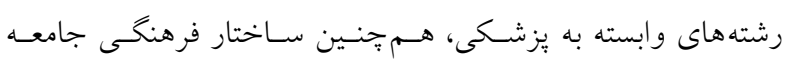

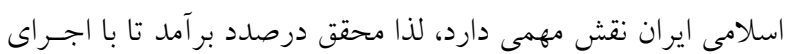

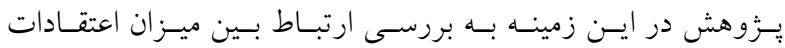
دانشجويان اين دانشكاه و سلامت روان ايشان بيردازد.

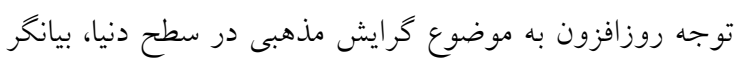

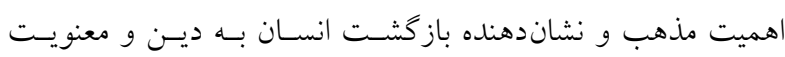

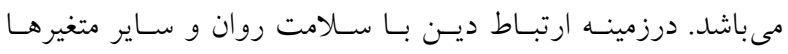
يُزوهشهاى متعددى صورت گرفته كه از آنها مى توان به مطالعـات

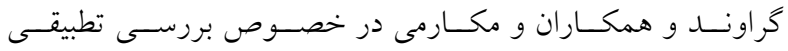

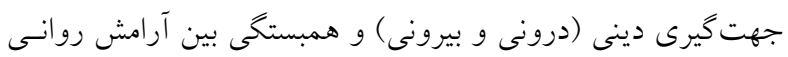

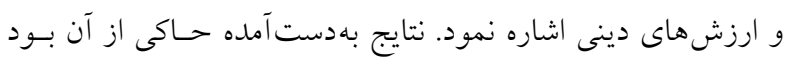

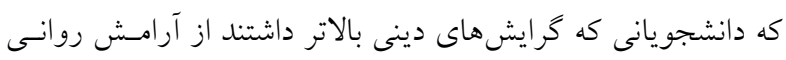
بيشترى برخوردار بودند. 19 19 در يزوهشى ديخر كه صولتى، ربيعى و شريعتى با هدف تعيين رابطه جهت گيرى مذهبى و سلامت روان در درد 
طبقهبندى شده است. "مشخصات دموكر افيكى كـه در ايسن مطالعـه بررسى گرديد شـامل سـن، جــن، وضـعيت تأهـل، رشـته و تـرم تحصيلى و وضعيت شغلى بودند.

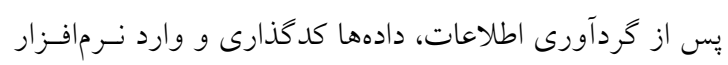
كرديد. براى توصيف دادهها از شاخص هاى توصيفى (توزيــع

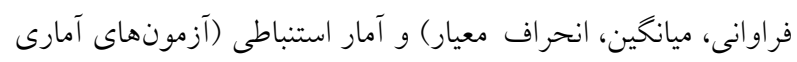

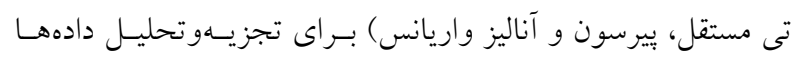
استفاده كرديد.

يافته ها

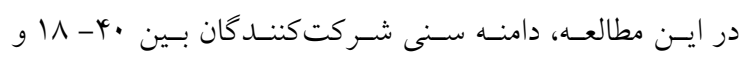

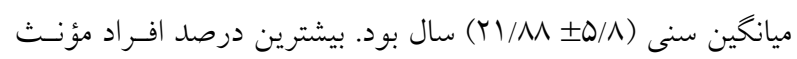

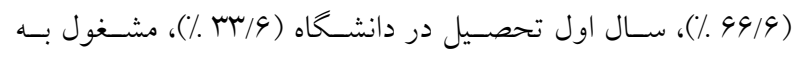

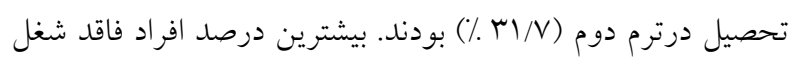
(

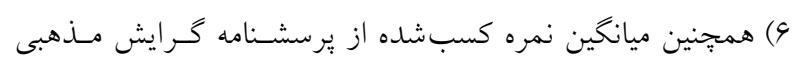

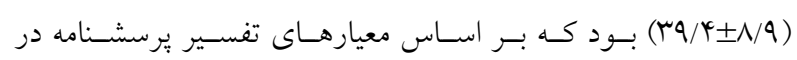
محدوده گرايش مذهبى متوسط مىباشد. ميانخين نمره كسبشده از

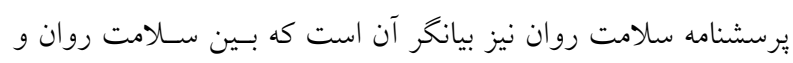
كرايش مذهبى رابطه معنى دارى وجود دارد.
روان با ب مؤال داراى جهار زيرمقياس علائم جسمانى، اضطراب،

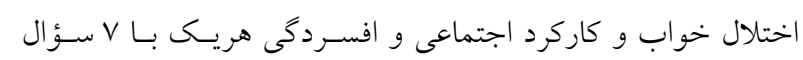

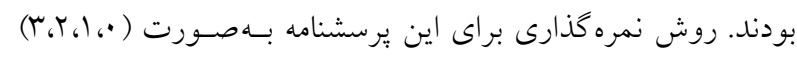

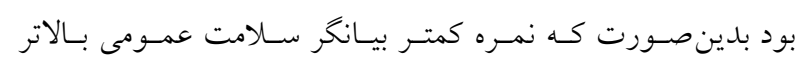

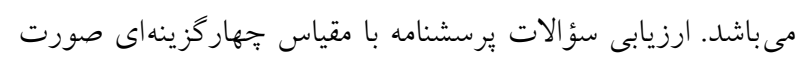

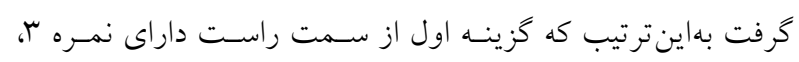
كزينه دوم نمره r، كزينه سوم نمره ا و گزينه آخر نمره صفر تعلـق

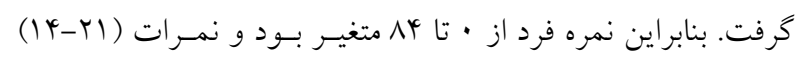
در هر زيرمقياس، نشانه وخامت وضع آزمودنى در آن زيرمقيـاس و

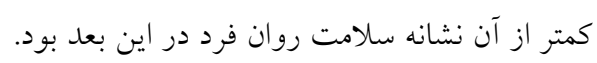

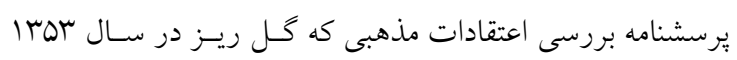

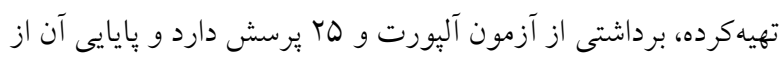

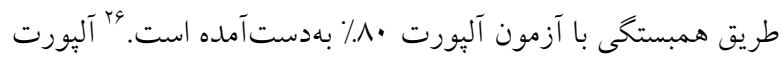

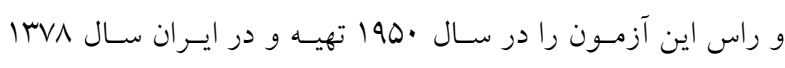
ترجمه و هنجاريابى شده اسـت. همسـانى درونسى آن توسـط جـان

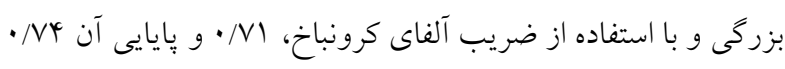
بهدستآمده است. باس هر سؤال داراى بنج مقياس و بر اساس مقيـاس

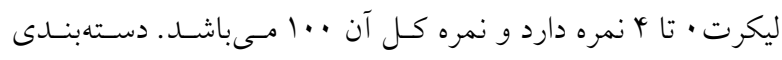

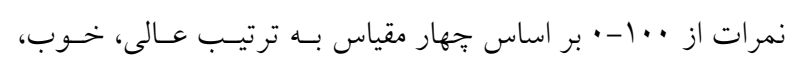

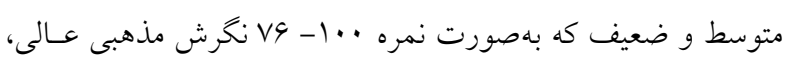
1-VD

\begin{tabular}{|c|c|c|c|c|c|}
\hline \multirow[b]{2}{*}{ تعداد كل } & \multicolumn{3}{|c|}{ وضعيت تأهل } & & \\
\hline & 9 & متأهل & مجرد & & \\
\hline ir & $\cdot$ & 1 & 11 & 1 & كرايش مذهبى \\
\hline YMI & 1 & $\notin \Delta$ & rmo & r & \\
\hline YI & . & r & 11 & $\mu$ & \\
\hline MIt & 1 & 49 & rar & & تعداد كل \\
\hline
\end{tabular}




\begin{tabular}{|c|c|c|c|c|c|}
\hline & & \multicolumn{3}{|c|}{ شغل } & \multirow[b]{2}{*}{ تعداد كل } \\
\hline & & غير شاغل & شاغل & كار دانشجوئى & \\
\hline & 1 & 1. & r & . & Ir \\
\hline & r & $r \cdot 1$ & v. & 11 & TAY \\
\hline & $r$ & 11 & 1. & . & r \\
\hline تعداد كل & & TrY & Nr & 11 & mis \\
\hline
\end{tabular}

\begin{tabular}{|c|c|c|c|c|}
\hline & \multicolumn{3}{|c|}{ كرايش مذهبى } & \multirow{2}{*}{ نعداد كل } \\
\hline & 1 & $r$ & $r$ & \\
\hline 1 & 0 & $\wedge$. & 9 & 91 \\
\hline$r$ & 1 & vq & 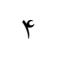 & $\wedge 1$ \\
\hline$r$ & 1 & 49 & $\varphi$ & $\Delta F$ \\
\hline$r$ & 1 & ro & r & r \\
\hline تعداد كل & $\wedge$ & re. & 19 & rGY \\
\hline
\end{tabular}

اين همبستخى تا سطح معينسى بايسـار بــوده و از آن بـه بعــ نتيجـهـ

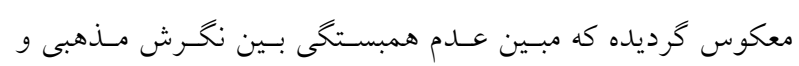

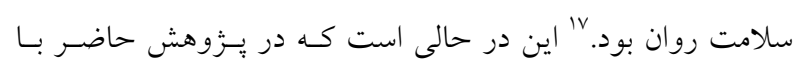

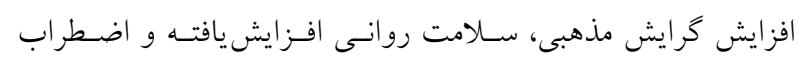
كاهش مى يابد. بسيارى از مطالعات و يزوهشئها نيـز اجمـالاً نشـان

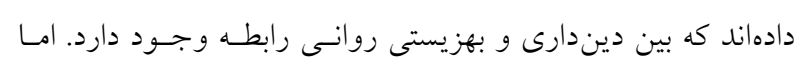

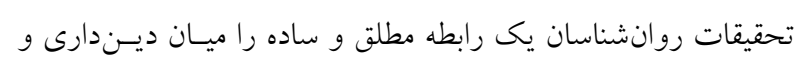
بهزيستى به دست نداده است، بلكه اين تحقيقات يافتهاى ناهمسان

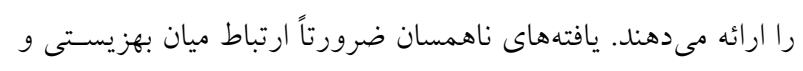

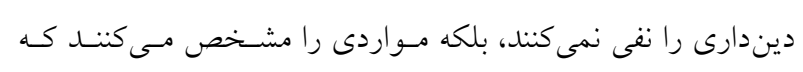

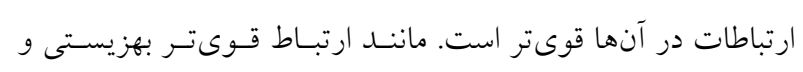

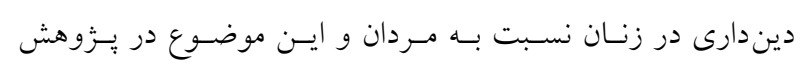

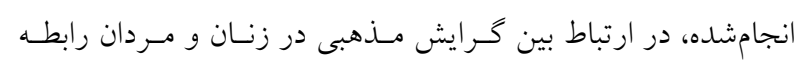

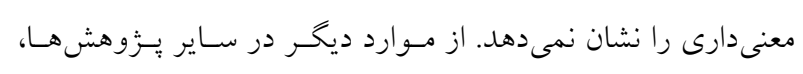

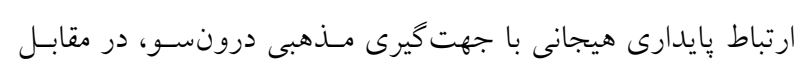

\section{بحث و نتيجه كيرى}

يافتهاى يزوهش حاضر نشان مى دهد كه بين سلامت اضطرابى

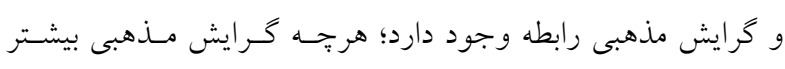

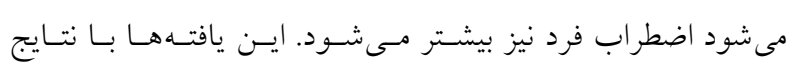

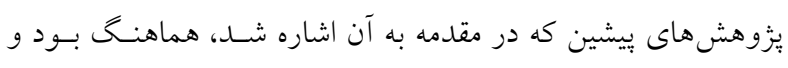

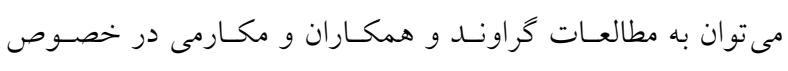
بررسى تطبيقى جهت گيرى دينى (درونى و بيرونى) و همبستخى بين

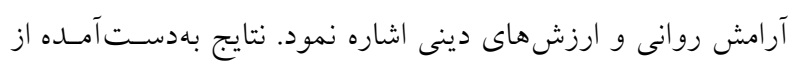

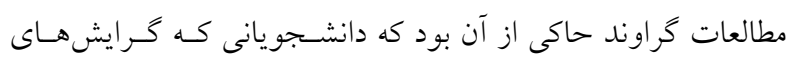

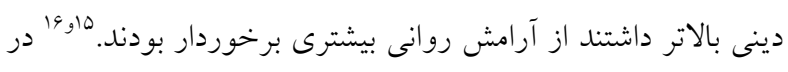

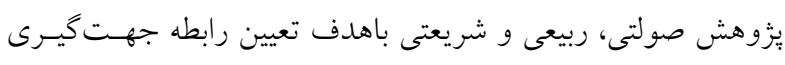

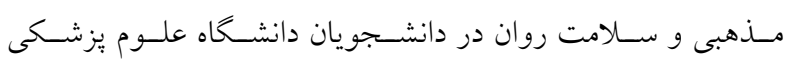
شهركرد نيز يافتها نشان داد هر جهه ميزان جهت گيرى مذهبى بيشـتر مى شود، همبستخى آن با سلامت روان آزمودنى ها بيشتر مىشوده. اما 


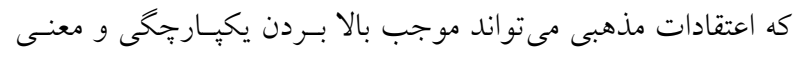

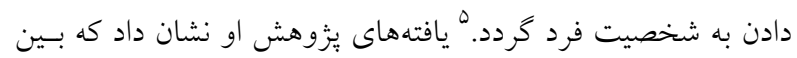

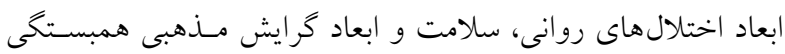

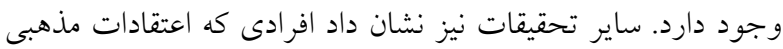
قوى ترى دارند سازگارى بهترى با موقعيتهـاى استرسى دارنــ، از عملكرد تحصيلى و حمايت اجتماعى بالاترى برخوردارند، اضطراب

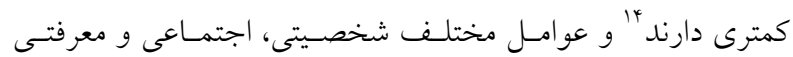

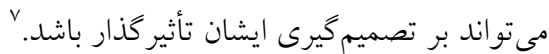
نتايج نشان داد كه بين كرايش مذهبى و متغيرهاى جنسيت، سن

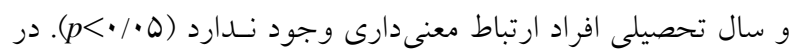
بررسى ارتباط بين گرايش مذهبى، جنبه هاى مختلف سلامت روان و

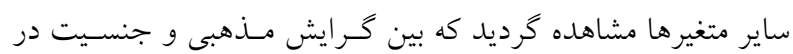
زيــر مقيـاسهــاى اضـطراب و افسـردخى سـلامت روان ارتبــاط معنسى دارى وجــود دارد. ولـى ايسن ارتبـاط در زيــر مقيـاس علائسم جسمانى وجود ندارد و در زيرمقياس كـاركرد اجتمـاعى بـه ميـزان

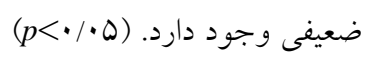

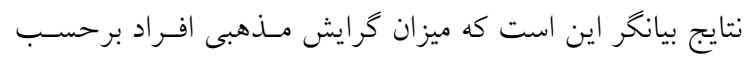
جنسيت مى توانـــد ميـزان احسـاس اضـطراب و افسـردكى فـرد را

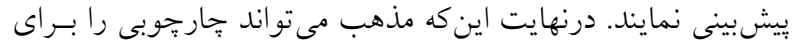
نظام روانشناختى فرد فراهم كند كه او را از طريـق تقويست نيـروى خويشتندارى به حالتى بايدار در عواطف و هيجاناتش سـوق دهـــ.

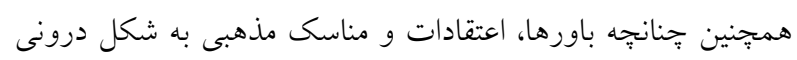

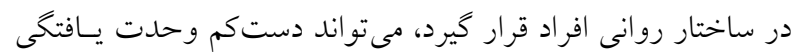
فرد را تضمين كندو سلامت روانى وى را فراهم نمايد.

1. Roshaninejad, Mahindokht. et al. The Relationship Between Religious Beliefs And Mental Health. Iranian Journal of Nursing and Midwifery., The Thirteenth Year. Summer 1379; 61(93). [In Persian]

2. Navabakhsh, Merdad. Et al. A Survey of Religious Commitment Islamic Azad University of Garmsar. Journal of Social Science. The Third Year. Autumn 1388; 3:91. 61. [In Persian]

3. Divsalar, kuros. et al. The Relationship Between Religious Activity And Smoking Students of The

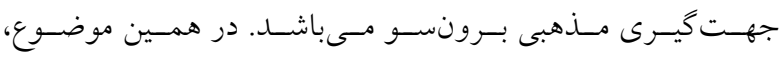

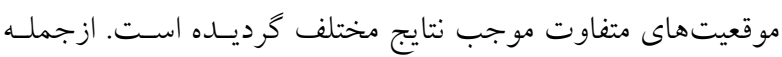
اين كه ارتباط يايدارى هيجانى با جهت گيــى مــهبى درونسـو در

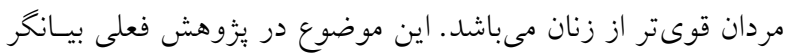
تفاوت سطوح سلامت و گر ايشهاى دينى در مردان وزنـان نيست. محمدى نيز در مطالعه خود نشان داد كه بين مذهب و بيمـارىهـاى

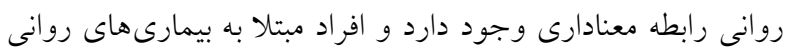

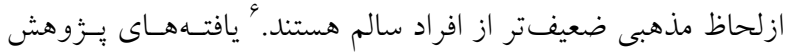

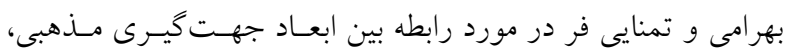
نشـان داد كـهـه بـين ابعـاد اخــتلالهــاى روانسى، سـلامت و ابعـاد

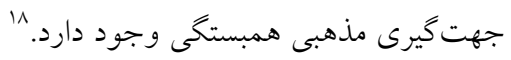

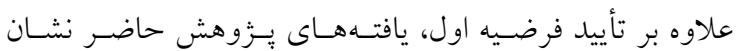

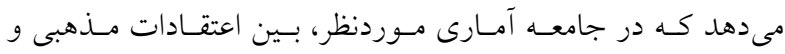
سلامت روان دانشجويان ارتبـاط وجـود دارد و ايسـن يافتـه تأييـدى است بر ارتباط گر ايش مذهبى با عوامل روانى دانشجويان. يـرّوهش

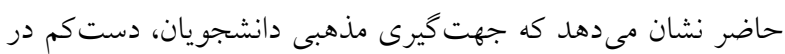

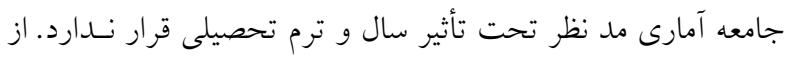

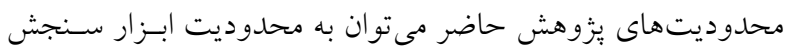

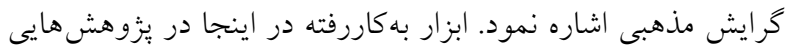

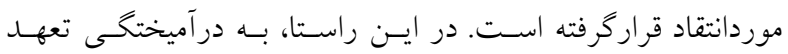

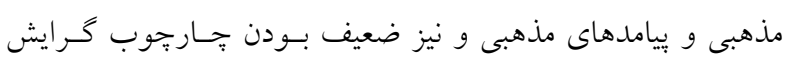

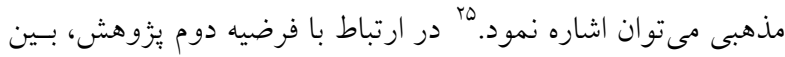

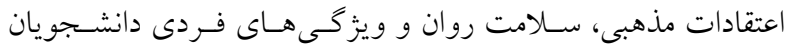

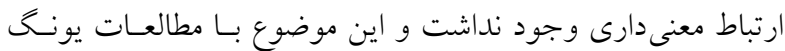
مطابقت داشت و او در خلال فعاليتهاى رواندرمانى خود دريافت

\section{منابع}

University of Kerman. Journal of Medicine and Purification. Fall 1386; XVI(67):63-69. [In Persian]

4. Sedighi Arfaei Fariborz, et al. Relationship Between Religious Orientation And Happiness in Students' Coping Styles. Journal of Religion and Psychology. The Fifth Year. Autumn 1391; 3: 135- 163. [In Persian]

5. Karbalaei Harfteh, Fateme Soghra. et al. The Relationship Between The Islamic Faith And Mental Health. Journal of Educational Sciences. 1386; 2: 81-90. [In Persian] 
6. Noorizadeh, Maryam.et al. On the occasion of World Mental Health Day-2012 October 10. Payam Moshaver. 1391;12(122):1-4.[In Persian]

7. Mahmoodi, Nahidolmoluk. et al. Factors Affecting Risk Students. Applied Sociology. Applied Sociology. 1389 Year Twenty (38 consecutive) 2: 35-56. [In Persian]

8. Mosalinejad L, Amini M. Study of Relationship between of Achievement and Mental Health Status of Two Groups Students in Jahrom University of Medical Sciences. Quarter J Fundament Mental Health 2004; 6(21): 71-76.

9. Abolghasemi A, Javanmirry L. The Role of Social Desirability, Mental Health and Self-efficacy in Predicting Academic. Achievement of Female Student. J School Psychol 2010; 1(2):6-20.

10. Gammari F, Mohammadbeigi A, Mohammadsalehi N. The Association between Mental Health and Demographic Factors with Educational Success in the Students of Arak universities. JBabol Med Sci 2010; 12(supp 1): 118-124.

11. Rezai R. Beheshti Z, Hajhoseini F, Seied J. Study of Compare Mental Health in Primary and Latest Nursing Students. Iran J Nurs Res 2006; 1(3): 67-74.

12. Adham D, Salem Safi P, Amiri M, Dadkhah B, Mohammadi M. Mozaffari N. The Survey of Mental Health Status in Ardabil University of Medical Sciences Students in 2001-2008. J Ardabil Univ Med Sci Health Ser 2008; 8(3):229-234.

13. Musavi, Fateme. et al. The Effect of Stress on Mental Health of Medical Students of Islamic Azad University. Iranian Journal of Surgery 1391; (1): 20-30. [In Persian]

14. Sedighi, Arfaei. et al. Relationship Between Religious Orientation And Happiness in Students' Coping Styles. Journal of Psychology and religion. Autumn 1391; 3: 135-163. [In Persian]

15. Geravand, Hushang. et al. A Comparative Study of Religious Orientation (Internal And External). Journal of Psychology and religion. Spring 1391; 1: 103- 79. [In Persian]

16. Makaremi, Azar. The Correlation Between Mental Peace And Religious Values. Proceedings of The Conference on The Role of Religion in Mental Health. Persian Date Azar 1376. [In Persian]

17. Solati, Seyed Kamal. et al. The Relationship Between Religious Orientation And Mental Health. Journal of
Qom University of Medical Sciences. 1390; (3) 5: 41. 48. [In Persian]

18. Bahrami, Hadi. et al. The Relationship Between Religious Orientation, Mental Health And Psychological Disorders. Journal of Developmental Psychology. 1384. ; 5: 35. [In Persian]

19. Ashtiani, Ali. et al. Psychological Tests, Personality And Mental Health Evaluation. Tehran Publications. 1388 : 315-309. [In Persian]

20. Nurbala, Ahmadali. et al. Validated 28-item General Health Questionnaire As a Screening Tool For Mental Disorders in Tehran. Journal Wise, 1387;4: 47-53. [In Persian]

21. Fathi Ashtiani, Ali. Psychological Tests, Personality And Mental Health Evaluation. Publications Besat. 1388. [In Persian]

22. Saatchi, Mahmud. et al. Psychological Tests. Editing And Publishing. 1389. [In Persian]

23. Gholjaei, Fereshte. et al. General Health Status And Quality of Sleep in Shifts Fixed And Circulating Nurses. Journal of Medical Science Research. 1389;13 (1): 47 50. [In Persian]

24. Janbozorgi, Masoud. Religious Orientation And Mental Health (Medical Research). Shahid Beheshti University of Medical Sciences and Health Services. 1386; (4) 31: 345 -350. [In Persian]

25. Golriz, Golshan. Research For Preparation of Religious Attitude And The Relationship Between Religious Attitudes And Personal Characteristics With Other Feedback. Thesis Psychology, Faculty of Letters and Human Sciences Tehran University. 1353. [In Persian]

26. Ebrahimi, Amrollah. et al. Factor Structure, Reliability And Validity of Religious Attitude Scale. Journal of Mental Health. 1387; 10(38): 107- 116. [In Persian]

27. Sadeghi, Mohammadreza. et al. The Religious Attitude And Mental Health in Students of Mazandaran University of Medical Sciences. Journal of Mazandaran University of Medical Sciences. 1389; (75) 20: 71-75. [In Persian]

28. Sadri, Jamshid. et al. Examine The Relationship Between Religious Beliefs And Mental Health. A Case Study of Islamic Azad University, Abhar. Journal of Behavioral Sciences 1389; 2 (3): 123- 138. [In Persian] 